\title{
REGIONAL LEVEL OF INCLUSIVE DEVELOPMENT
}

\author{
SHASHYNA V. Maryna ${ }^{1}$, BUTKO P.Mykola ${ }^{2}$, TULCHYNSKA O. Svitlana ${ }^{3}$ \\ ${ }^{1}$ Faculty of Management and Marketing, Igor Sikorsky Kyiv Polytechnic Institute, Kyiv, (UKRAINE) \\ ${ }^{2}$ Department of Management and Civil Service, Chernihiv Polytechnic National University, Chernihiv, (UKRAINE) \\ ${ }^{3}$ Department of Economics and Entrepreneurship, Faculty of Management and Marketing, Igor Sikorsky Kyiv Polytechnic \\ Institute, Kyiv, (UKRAINE) \\ E-mail: Shashyna.marina@gmail.com;
}

\begin{abstract}
The concept of inclusive development provides equal opportunities for all participants in access to the labor market and resource allocation. This concept emphasizes the equality of human capital, the ecological state of the environment, social protection and food security. This concept is fundamentally different from the standard perception of economic growth, because it has broader goals than simply increasing incomes and GDP. It rejects the position that positive results are an automatic consequence of growth; here the basic condition is human development and increase of its well-being, reduction of poverty. Therefore, it is not the result of distribution that becomes primary, but the involvement in the process of social reproduction. An alternative system of characterization of the country's position according to the resulting indicator of the Inclusive Development Index was presented at the World Economic Forum in Davos. In this research the methodical development of the system of estimation of the index of inclusive development for regions of the NUTS 4 level of the European classification is resulted.
\end{abstract}

Keywords: equal opportunities, human capital, inclusive development, labor market, regional level.

JEL: A11

DOI: $10.5937 /$ intrev2102060S

UDC: $330.341: 005.952$

005.336 .4

COBISS.SR-ID 43531273 


\section{INTRODUCTION}

Dynamic integration of the concept of inclusive sustainable growth in developing countries is the basis for modifying the governance system to create a solid basis for the positioning of countries in the global economy through the participation of all citizens in economic growth and fair distribution of its results [1][2]. According to the International Policy Center, inclusiveness is becoming a key factor of alternative approaches to countering the dominance of the neoliberal paradigm and creating a place in development concepts to ensure universal participation in growth in both decision-making and growth [3].

Assessment of the level of inclusive development has been proposed by various international organizations. In particular, according to the IMF methodology, the emphasis is on social mobility and income distribution [4]; The OECD methodology focuses on different types of resources that can be measured at present and signify the well-being of future generations [5]. One of the most used methodological approaches is the one proposed by the World Economic Forum [6]. It takes into account both the direction of development, inclusiveness and generational succession. Given the recent challenges, the concept of inclusive development is promising for Ukraine [7][8].

Most scientific works contain a justification for inclusive growth as a basis for socio-economic development of the country, without dwelling on the definition of its parameters for national realities in the regional aspect. Focus on the theoretical basis of the basics of methodological description of inclusive growth is found in different interpretations. First of all, it should be noted that growth cannot be sustainable and effective in reducing poverty if it is not comprehensive [9][10].

Consideration of economic growth cannot take place without taking into account the distribution of income [9]. Income inequality decreases only in the case of faster income growth of the poorer sections of the population [10][11].

A theoretical interpretation of the growth of inclusive development by reducing inequality in relation to the most vulnerable groups is found in [4][11]. Growth through urban centers in urban areas, rural infrastructure or as a result of redistribution of basic resources between the center and the periphery [12], identification of equal opportunities for participation in social reproduction [13] and the level of inclusiveness is interpreted on the basis of the characteristics of the redistribution of social benefits. Such benefits may be aimed at roads, electricity, health care and education [11][13].

The practical implementation of theoretical directions for understanding inclusive growth and directions for its definition has been provided by a number of international organizations. An important role is given to the effective work of government and public institutions in the methods which were proposed by them. Their policy should be optimized, on the one hand, both in terms of creating conditions for comprehensive participation in GDP production, and on the other - to eliminate inequality in the distribution of the product created [14][15].

\section{METHODOLOGY}

The theoretical and methodological basis of this work is the assessment of the index of inclusive development, proposed by the World Economic Forum [6]. It combines the ideas of simultaneous consideration of growth and development, equal distribution of natural and financial resources and inclusiveness. To conduct the study, macroeconomic indicators that determine the level of inclusive development at the regional level were adapted. 




Fig. 1 Sub-indices of the integrated indicator of inclusion at the regional level Source: adapted by the authors based on the methodology of the World Economic Forum [6]

The data collection process was carried out on the basis of national standards of the formation of macroeconomic indicators and using data that was generated at the level of regional entities since the implementation of European legislation and statistical accounting standards in accordance with the specified parameters (Fig. 1).

To calculate the most complex indicator - the Gini coefficient (the degree of stratification of society by income) - for clarity we took a set of values of population distribution (\%) by the level of per capita that is equivalent total income per month, in UAH. The place of research is Kyiv region. This region is one of the most successful and comparable with Western European analogues in terms of socio-economic and innovative parameters of the region. The research period is 2018.

The total population of the region is divided into 11 equal initial groups according to the number of households of $9 \%$.

The line of actual inequality is drawn on the basis of data for interest income, which accounts for every 9\% of the population (Fig. 2).

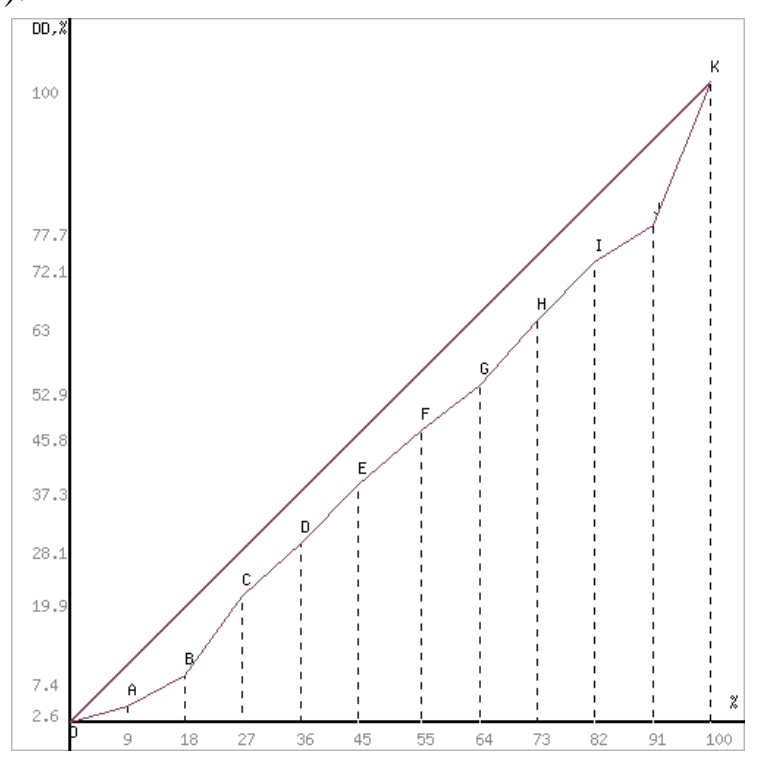

Figure 2. Graph of the Lorentz curve

Source: Created by the author according to the data 
If the first part of the population receives $2.6 \%$ of all income, then graphically it will be point $\mathrm{A}$. To obtain point $\mathrm{B}$, we need to sum up the next $9 \%$ of the population, etc.

To form the curve, we used the values from the 1st column of Table 1. It was made for the construction of the $\mathrm{X}$ axis and then we used the $3^{\text {rd }}$ column for the construction of the $\mathrm{Y}$ axis.

\begin{tabular}{|c|c|c|c|c|c|}
\hline $\begin{array}{c}\text { Percentage of } \\
\text { population } \\
\text { groups (pi) }\end{array}$ & $\begin{array}{c}\text { The amount of } \\
\text { money income of the } \\
\text { population, in \% of } \\
\text { the total } \\
\text { (qi) }\end{array}$ & $\begin{array}{c}\text { The share of money } \\
\text { income of the } \\
\text { accumulated } \\
\text { result, } \%\end{array}$ & $\begin{array}{c}\text { The area } \\
\text { of a } \\
\text { triangle }\end{array}$ & $\begin{array}{c}\text { The area of } \\
\text { the } \\
\text { rectangle }\end{array}$ & $\begin{array}{c}\text { The total } \\
\text { area of the } \\
\text { figure, Si }\end{array}$ \\
\hline 9 & 2.6 & 2.6 & 11.7 & & \\
\hline 18 & 4.8 & 7.4 & 21.6 & 23.4 & 11.7 \\
\hline 27 & 12.5 & 19.9 & 56.25 & 66.6 & 122.85 \\
\hline 36 & 8.2 & 28.1 & 36.9 & 179.1 & 216 \\
\hline 45 & 9.2 & 37.3 & 41.4 & 252.9 & 294.3 \\
\hline 55 & 8.5 & 45.8 & 38.25 & 335.7 & 373.95 \\
\hline 64 & 7.1 & 52.9 & 31.95 & 412.2 & 444.15 \\
\hline 73 & 10.1 & 63 & 45.45 & 476.1 & 521.55 \\
\hline 82 & 9.1 & 72.1 & 40.95 & 567 & 607.95 \\
\hline 91 & 5.6 & 77.7 & 25.2 & 648.9 & 674.1 \\
\hline 100 & 22.3 & 100 & 100.35 & 699.3 & 799.65 \\
\hline & & & & & 4111.2 \\
\hline
\end{tabular}

\section{Source: Author's own calculations}

Since the coefficient of income concentration (Gini index) represents the ratio of the area of the figure formed by the Lorentz curve and the line of absolute equality (S1) to the area of the whole figure of the triangle OGE, we obtain the following results of Gini coefficient calculations given in table. 2.

Table 2. The results of the calculation of the Gini coefficient

\begin{tabular}{|c|c|c|c|}
\hline $\mathbf{p}_{\mathbf{i}}$ & $\mathbf{q} \mathbf{i}$ & $\mathbf{p}_{\mathbf{i}} \mathbf{q}_{\mathbf{i}+\mathbf{1}}$ & $\mathbf{p}_{\mathbf{i}+\mathbf{1}} \mathbf{q}_{\mathbf{i}}$ \\
\hline 0.09 & 0.026 & 0.00666 & 0.00468 \\
\hline 0.18 & 0.074 & 0.03582 & 0.01998 \\
\hline 0.27 & 0.199 & 0.07587 & 0.07164 \\
\hline 0.36 & 0.281 & 0.1343 & 0.1265 \\
\hline 0.45 & 0.373 & 0.2061 & 0.2052 \\
\hline 0.55 & 0.458 & 0.291 & 0.2931 \\
\hline 0.64 & 0.529 & 0.4032 & 0.3862 \\
\hline 0.73 & 0.63 & 0.5263 & 0.5166 \\
\hline 0.91 & 0.721 & 0.6371 & 0.6561 \\
\hline 1 & 0.777 & 0.91 & 0.777 \\
\hline Total & 1 & - & 3.0569 \\
\hline
\end{tabular}

Source: Author's own calculations

Accordingly, the Gini coefficient is equal to:

$$
\mathrm{K}_{\mathrm{L}}=\sum \mathrm{p}_{\mathrm{i}} \mathrm{q}_{\mathrm{i}+1}-\sum \mathrm{p}_{\mathrm{i}+1} \mathrm{q}_{\mathrm{i}}=3.22635-3.0569=0.16945
$$

The value of the coefficient varies from 0 to 1 . In this case, the greater its value deviates from 0 , the higher the concentration of income in a particular population group.

The calculation of the integrated inclusion index is made using the following considerations.

Let $X=\left\{x_{1}, x_{2}, x_{3}, \ldots, x_{n}\right\}, Y=\left\{y_{1}, y_{2}, y_{3}, \ldots, y_{n}\right\}$ - vectors of estimation of inclusion parameters for the region of Ukraine in two conditions, - the number of inclusion parameters that take into account. Conventional approaches to aggregation of parameter set values to obtain generalized or integral values (additive, multiplicative, probabilistic, etc.) [5] are not applicable in this case, because the considered parameters have different physical meaning and different units of measurement.

To analyze the subject area, the author proposes to use a vector representation of the processed data, because it has a strict mathematical justification [16]. The set of values of the parameters by which the inclusion of the region is estimated were considered as the coordinates of the ends of the vectors. These vectors correspond to the conditions of the region in the multifactor relevance space.

So, the angle between the vectors corresponding to the two conditions of the region (in different years or real and ideal) shows the degree of their difference in this space and the cosine of this angle is a convenient metric because it 
varies from 0 to 1 . Thus, values of the cosine of the angle close to 0 determine the states of inclusion of the regions as those that are most distant (in this case, close to the perpendicular) vector of the ideal state, and, conversely, those close to 1 provide motion in the correct view of the ideal vector, direction.

The cosine of the angle between the vectors of inclusion estimates is determined as follows:

$$
\cos (\varphi)=\frac{\sum_{i=1}^{n} x_{i} y_{i}}{\sqrt{\sum_{i=1}^{n} x_{i}^{2}} \sqrt{\sum_{i=1}^{n} y_{i}^{2}}}(1)
$$

To ensure the legitimacy of this approach, so that the difference in the ranges of change of indicators does not affect the results of calculations [2,9], the normalization of data from table. 3 as follows. For indicators that should ideally tend to the maximum values, according to the formula:

$$
x_{i j}^{n o r m}=\frac{x_{i j}-\min _{i} x_{i j}}{\max _{i} x_{i j}-\min _{i} x_{i j}}
$$

here $x_{i j}^{\text {norm }}$ - new normalized value of $i$ indicator for $x_{i j}^{\text {norm }}$-й year, $x_{i j}$ -

abnormal value of the indicator, $\min _{i} x_{i j}$ - the minimum value for the $i$ indicator, taking into account the values for all areas for which the analysis is performed, and the ideal value defined in Table $3 ; \max _{i} x_{i j}$ - the maximum value for the $i$ indicator, taking into account the values for all areas for which the analysis is performed.The ideal value is defined in table. 3 . For indicators that should ideally tend to the minimum values, the normalization of data is calculated by the formula:

$$
x_{i j}^{n o r m}=\frac{\max _{i} x_{i j}-x_{i j}}{\max _{i} x_{i j}-\min _{i} x_{i j}}
$$

Analysis of the results of the proposed methodological approach has the following meanings.

To select the ideal value of the parameter of inclusion of the subject area, which is considered on the example of

\begin{tabular}{|c|c|c|c|c|}
\hline \multirow{2}{*}{ Inclusion indicators } & \multicolumn{2}{|c|}{ Years } & \multirow{2}{*}{ Ideal value } & \multirow{2}{*}{$\begin{array}{c}\text { Direction of } \\
\text { development } *\end{array}$} \\
\hline & 2017 & 2018 & & \\
\hline y1 & 46730,30 & 60175,79 & 200000,00 & Max \\
\hline y2 & 9,51 & 10,27 & 50,00 & $\operatorname{Max}$ \\
\hline y3 & 491470,32 & 586172,65 & 2000000,00 & Max \\
\hline y4 & 71,18 & 70,51 & 100,00 & Max \\
\hline y5 & 7748,00 & 9737,80 & 20000,00 & Max \\
\hline y6 & 9,67 & 31,18 & 0,00 & Min \\
\hline y7 & 31,10 & 21,00 & 0,00 & Min \\
\hline y8 & $-0,87$ & $-4,26$ & 50,00 & Max \\
\hline y9 & $6,47 \mathrm{E}-04$ & $4,84 \mathrm{E}-04$ & 0,00 & Min \\
\hline y10 & 43,44 & 44,84 & 75,00 & Max \\
\hline y11 & 69,51 & 70,69 & 50,00 & Min \\
\hline
\end{tabular}
the progressive region of Kyiv region, the initial data on the proposed indicators in Fig. 1 is presented in Table 3.

Table 3. Ideal value of inclusion parameters for the subject area

* - max mark means that ideally the value of the parameter should tend to the maximum, min mark - to the minimum

Source: Author's own calculations based on factual data Statistical information [17]

According to the proposed methodological approach to the normalization of the obtained values and given directions in Table 3, we obtain normalized inclusion indicators, which can be comparable in the autonomous mode of Table 4. 
Table 4. Values of normalized indicators of inclusion and calculation of the integrated indicator for the selected level of regional grouping

\begin{tabular}{|c|c|c|}
\hline \multirow{2}{*}{ Inclusion indicators } & \multicolumn{2}{|c|}{ Years } \\
\cline { 2 - 3 } & $\mathbf{2 0 1 7}$ & $\mathbf{2 0 1 8}$ \\
\hline $\mathbf{y} 1$ & 0,298 & 0,407 \\
\hline $\mathbf{y 3}$ & 0,202 & 0,214 \\
\hline $\mathbf{y 4}$ & 0,151 & 0,202 \\
\hline $\mathbf{y 5}$ & 0,016 & 0,010 \\
\hline $\mathbf{y 6}$ & 0,215 & 0,328 \\
\hline $\mathbf{y 7}$ & 0,764 & 0,690 \\
\hline $\mathbf{y 8}$ & 0,162 & 0,374 \\
\hline $\mathbf{y 9}$ & 0,000 & 0,070 \\
\hline $\mathbf{y 1 0}$ & 0,921 & 0,895 \\
\hline y11 & 0,344 & 0,369 \\
\hline Integral indicator Incl & 0,308 & 0,251 \\
\hline & $\mathbf{0 , 8 8 6}$ & $\mathbf{0 , 9 2 4}$ \\
\hline
\end{tabular}

Source: Author's own calculations

As can be seen from the evaluation parameters, it can be noted that the Kyiv region is quite low in terms of a set of indicators that determine inclusiveness: household income, income inequality, relative poverty and life expectancy. Although, in general, the obtained values of the integrated indicator are positively dynamic and have a fairly high level of value, which is close to one, and that is why the hypothesis of proportionality from 0 to 1 .

\section{RESULTS AND DISCUSSION}

Assessing the inclusiveness of economic growth according to the methods of international economic institutes in general is a mathematical toolkit, which is used to calculate the consolidated index. For its calculation, groups of indicators are used that characterize the dynamics of various processes that have an impact on the resulting inclusive growth, as well as regression equations aimed at quantifying the relevant factors.

However, today there are a number of problems related to both the interpretation of the most inclusive development and the ways of its evaluation and use of results.

The first problem is related to various aspects of understanding what should be the result of inclusive development: overcoming poverty, involving all segments of the population in the process of social reproduction, improving the quality of education, involvement of maximum area as resource potential, identifying opportunities to improve welfare in country. Such discrepancies give rise to a large theoretical and practical basis of visions of the resulting factor.

The second problem is the difference in traditions and standards of statistical accounting at the level of different regional groups, which are typical for the countries of the EU and Ukraine (the relevant standards are implemented only at 61\%) [15][17].

The third problem is the comparability of the obtained results, which can be indicative at the level of national regions and those ones which were obtained by international indices. According to these indices further recommendations are developed for strategic development at the level of the country and a smaller level of regional groups.

The fourth problem is revealed in the methods of the applied mathematical apparatus, which can eliminate the causes and consequences of mistakes, which will strongly influence the resulting factors regarding the current and future directions of development of the region.

According to Gupta \& Vegelin [2], inclusiveness is becoming a key focus of alternative approaches to counter the dominance of the neoliberal paradigm and create a place in development concepts for the poorest people and the environment. At the same time, experts representing the World Economic Forum [6] argue that socioeconomic inequality is largely dependent on endogenous challenges. Therefore, priorities should be identified and assessed as such, as it is possible, taking into account the internal potential for inclusive development of the region. In terms of small spatial groups, it becomes available to study this issue on the basis of adaptation of the proposed approach, taking into account the simplicity and logic of the device used. This does not contradict the main provisions of the International Inclusion Index and does not violate the basic theoretical provisions on the correlation between GRP growth rates and poverty. 


\section{CONCLUSIONS}

The study is unique for several reasons. First of all, it provides an opportunity to compare the results of the calculation of the index of inclusive development with world counterparts. Secondly, it addresses the issue of assessing the development of regions not only by the parameters of several interrelated variables such as GRP, household income, capital investment at the regional level, which are more common in domestic practice.

It is also proposed to adapt these indicators taking into account the involvement and imitation of generations, which is quite promising in the further implementation of European legislation, building a national model of improving the welfare of the population. Even for one of the most progressive regions of Ukraine, the issues of labor productivity, life expectancy and demographic burden remain relevant. All these factors should be included in the regional development strategy and agreed with the national program for the formation of further development goals. The proposed methodological approach is logical and accessible in application. It can also provide taxonomy of information in comparison with existing global indices of inclusion.

\section{REFERENCES}

[1] Ranieri, R., \& Ramos, R. A. (2013). Inclusive Growth: Building up a Concept. Working Paper, No 104. Brazil: International Policy Centre for Inclusive Growth.

[2] Gupta, J., \& Vegelin, C. (2016) Sustainable development goals and inclusive development. Int Environ Agreements, 16, pp. 433-448. https://doi.org/10.1007/s10784016-9323-z .

[3] International Policy Centre (2019). Exploring and Strengthening the Intersections between Social Protection, Employment and Inclusive Growth. Available at: http://www.ipcundp.org/publication/26527.

[4] Anand R., Mishra S., \& Peiris S. (2013) Inclusive growth revisited: Measurement and evolution. VoxEU \& CERP, August 17. Available at: https://voxeu.org/article/inclusivegrowth-revisited-measurement-and-evolution

[5] OECD (2014). Framework for Inclusive growth. Paris: OECD. Available at: http://www.oecd. org/mcm/IG_MCM_ENG.pdf.

[6] World Economic Forum (2018). The Inclusive Development Index 2018. Summary and Data Highlights. Available at: http://www3.weforum.org/docs/WEF_Forum_IncGrwth_2018.pdf

[7] Y .Raziani, S. Raziani, Investigating the Predictors of Overweight and Obesity in Children. Int. J. Adv. Stu. Hum. Soc. Sci., 2020, 9(4), 262-280. DOI: http://dx.doi.org/10.22034/ijashss.2020.256464.1023

[8] Bozorgian, A. (2020). Investigating the Unknown Abilities of Natural Gas Hydrates. International Journal of Advanced Studies in Humanities and Social Science, 9(4), pp. 241251.http://dx.doi.org/10.22034/ijashss.2020.255633.1021

[9] Berg A., \& Ostry J. (2011). Equality and Efficiency. Finance \& Development, 48(3). Available at: https://www.imf.org/external/pubs/ft/fandd/2011/09/Berg.htm.

[10] Dollar, D., \& Kraay A. (2002). Growth Is Good for the Poor. Journal of Economic Growth, 7(3), pp. 195-225.

[11] Rodríguez-Pose, A. \& Tijmstra, S.A.R. (2007). Local economic development in subSaharan Africa. Environment and Planning C: Government and Policy, 25(4), pp. 516-536.

[12] Ali, I., \& Son, H.H. (2007). Measuring inclusive growth. Asian Development Review, 24(1), pp. 11-31.

[13] Lawson, V. (2010). Reshaping economic geography? Producing spaces of inclusive development. Economic Geography, 86(4), pp. 351-360.

[14] Sajjadi, S. M., \& Ansari, S. (2019). Deschooling from Religious Education in Islamic Republic of Iran: Possibility and Necessity?. International Journal of Advanced Studies in 
Humanities and Social Science, 8(4), pp. 369-

382.http://dx.doi.org/10.33945/SAMI/IJASHSS.2019.4.6

[15] Kaviani, R. (2020). Formation Methods and Properties of Gaseous Hydrates. International Journal of Advanced Studies in Humanities and Social Science, 9(4), pp. 281290.http://dx.doi.org/10.22034/ijashss.2020.257698.1025

[16] Walt. S., Colbert S. C., \& Varoquaux G. (2011). The NumPy array: a structure for efficient numerical computation. Computing in Science and Engineering. 13 (2), pp. 22-30.

[17] Statistical information (2019). Main Department of Statistics in Kyiv region. Available at: http://kyivobl.ukrstat.gov.ua/content/sitemap.php3?lang=1 .

Article history:

Received 10 May 2021

Revision 25 June 2021

Accepted 15 July 2021 